This is the post-refereed, pre-print version of an article accepted for publication in Mnemosyne, @Brill Publishing. When published, the definitive version of record will appear at http://www.ingentaconnect.com/content $/ \mathrm{brill} / \mathrm{mne}$

\title{
Comparative Adjectives in Herodian
}

\begin{abstract}
This work examines how the grammarian Herodian (2nd Century) treated

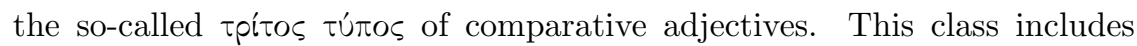
$\beta p \alpha ́ \sigma \sigma \omega \nu, \pi \alpha ́ \sigma \sigma \omega \nu, \gamma \lambda \dot{\sigma} \sigma \sigma \omega \nu, \beta \alpha ́ \sigma \sigma \omega \nu, \mu \alpha ́ \sigma \sigma \omega \nu, \vartheta \alpha \dot{\sigma} \sigma \sigma \omega \nu$ and $\dot{\varepsilon} \lambda \dot{\alpha} \sigma \sigma \omega \nu$, whose root vowels are dixpovos, i.e. their length is not indicated in the orthography. Nor is their length ascertainable from metrical evidence. Herodianic doctrine regarding these vowel lengths is investigated and shown to conflict with modern etymologies in some instances. The question arises whether we should trust Herodian or the etymologies.

These contradictions are best resolved by reviving, in modified form, Wackernagel's idea that Herodian reports specifically Attic root vowel lengths in exactly the instances where a suitable Attic form existed; Attic comparatives often differ from those in other dialects due to well-established vowel lengthening processes. But Herodian's citation of forms with non-Attic $-\sigma \sigma-$ rather than - $\tau \tau$ - is unexpected and suggests a more fundamental explanation: Herodian's account of these formations is probably based on the relevant Koine forms, where these existed. This conclusion may offer insights into the sources of Herodian's linguistic judgements more generally.
\end{abstract}

\section{Keywords}

Greek Linguistics; Grammatical tradition; Comparative adjectives; Etymology; Herodian 


\section{Introduction}

In this paper we will examine textual and linguistic questions raised by five very similar grammatical passages,${ }^{1}$ all of which appear to be derived from Herodianic material. ${ }^{2}$ They constitute the main independent evidence for the length of the root vowel in a small group of comparative adjectives and are of interest because the facts as Herodian gives them are not always easy to reconcile with what we think we know about the etymology of these forms. I argue that there is a ready explanation for the problematical vowel lengths and their distribution. But this approach raises questions concerning the linguistic material which Herodian had at his disposal, how the forms Herodian was describing related to the spoken language of his own time, and the ways in which historical information about vowel length in some archaic forms might have been accessible to him.

\section{Categories and Coverage}

In ancient Greek grammatical theory comparative adjectives were designated as ourxpıtıx' '(words) for comparing'. These could be further specified ac-

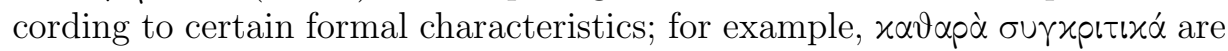

\footnotetext{
${ }^{1}$ This article is based on a paper which I gave at a workshop on the Greek grammarian Herodian at the University of Oxford in June 2010. I am very grateful to Dr Philomen Probert for inviting me to participate in the workshop and for subsequently encouraging me to prepare this work for publication. I owe her a very great debt of gratitude for hours of interesting and fruitful discussion of Herodianic questions, for making key suggestions in the development of this paper, and for innumerable helpful insights and comments. She also read the final manuscript and saved me from numerous errors. I am grateful to Dr Stephanie Roussou for allowing me to see her doctoral thesis. I am also most grateful to the two anonymous reviewers for their useful comments and corrections. Needless to say, all remaining errors are my responsibility.

${ }^{2}$ The attribution of a particular grammatical doctrine or even a particular grammatical treatise to Herodian can be difficult. There is an intrinsic difficulty in establishing firm attributions for grammatical texts or portions of texts where material from a long tradition of scholarship has been reused over time. Most of the works typically attributed to Herodian have been transmitted in a rather indirect fashion, often through epitomes or quotations in other grammatical works (see Dyck 1993 and Dickey 2007:75-77). Such considerations suggest an inclusive approach to the available evidence in the first instance. In this study, we will take into account grammatical works thought to have been written by Herodian himself, works which may have been produced by other scholars in antiquity working in the Herodianic tradition, and even works which are probably much more recent where their authors seem to have had access to a richer body of apparently genuine Herodianic material than we now possess. This broad approach must be counterbalanced with a critical perspective on the reliability of such testimony.
} 
those with a vowel in the penultimate syllable of the citation form (including

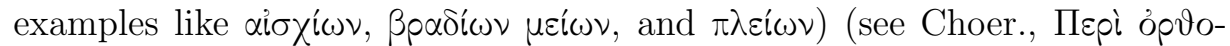

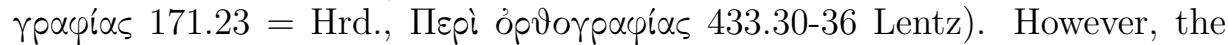
passages of principal interest from an etymological point of view are those where independent knowledge of vowel length is totally reliant on the grammatical tradition, i.e. where length is not indicated in the spelling and metrical evidence cannot be of assistance (i.e. in closed syllables). Comparatives with these characteristics were also of interest to Herodian, and the main focus of this enquiry will be the passages treating these issues.

\subsection{Three Major Categories}

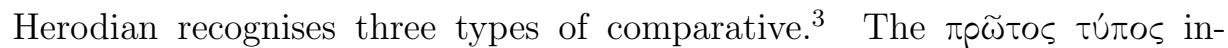
cludes forms built using the productive suffix - $\varepsilon \rho \rho-\varsigma$, found in examples

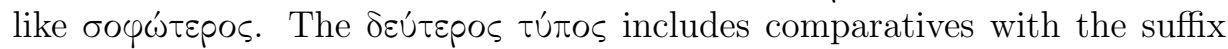
$-i \omega \nu$, found in $\dot{\eta} \delta i \omega \nu$ etc. Herodian's choice of examples shows that the rpítos

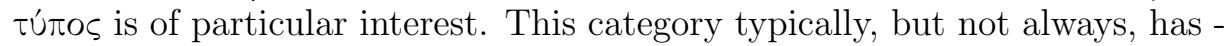
$\sigma \sigma-$ in the stem and includes well-established forms such as $\beta \alpha ́ \sigma \sigma \omega \nu, ~ \varepsilon ่ \lambda \alpha ́ \sigma \sigma \omega \nu$,

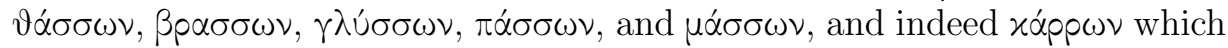
lacks the usual $-\sigma \sigma-;^{4}$ but various other examples of this category do not have any independent attestation in Greek and are supported only by the

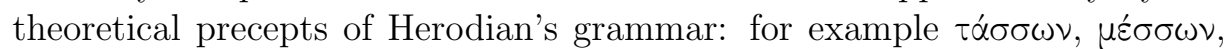

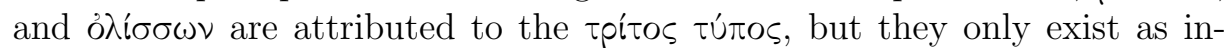
termediate formations in the grammar, providing the derivational basis for $\vartheta \alpha ́ \sigma \sigma \omega \nu, \mu \varepsilon \dot{\varepsilon} \zeta \omega \nu / \mu \varepsilon \dot{\zeta}\left(\omega \nu\right.$, and $\dot{\partial} \lambda i \zeta \omega \nu$ respectively. ${ }^{5}$

These three types of comparative adjective were seen as standing in a predictable derivational relationship with one another and it was clearly not considered terribly relevant that one or more members of a theoretical maximal set of forms was not actually in use at any stage in Greek. Hence

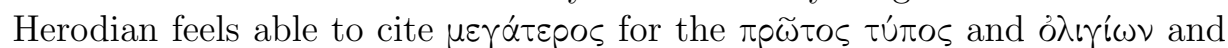

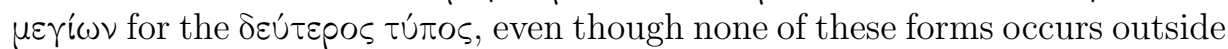
grammatical texts. Such internally-motivated forms could be invoked when necessary, in order to provide an explanatory basis for other formations. This point will prove to be important when we attempt to resolve certain textual

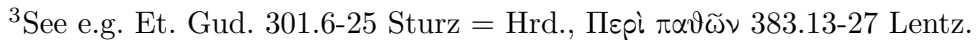

${ }^{4}$ See Et. Gud. 301.6-25 Sturz = Hrd., Пврi $\pi \alpha \vartheta \widetilde{\omega} \nu$ 383.13-27 Lentz.

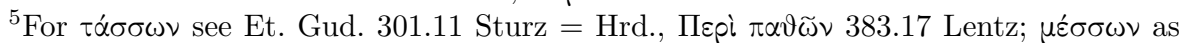
an intermediate form is implied by the Herodianic scholion $\Sigma$ Il. 18.519b (A), cf. Hrd.,

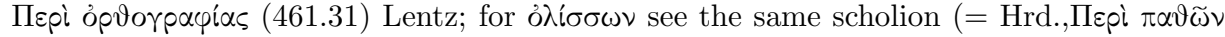

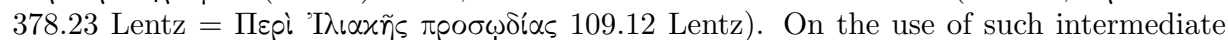
forms, see Dickey (2007:114).
} 
difficulties in two of our passages and when we try to assess the overall scope of the rules which Herodian sets out.

\subsection{The Historical Basis and Unity of the Formation}

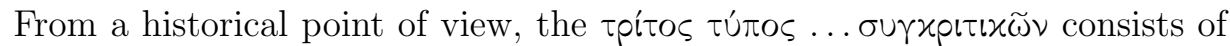
'primary' comparatives, which is to say comparatives built directly from roots rather than adjectival stems. They were originally formed using the inherited suffix $*_{\text {-yos- }}$ (cf. Ved. -yas-) and a variant ${ }^{*}$-yon- (which eventually ousted ${ }^{*}$-yos-). ${ }^{6}$ However, the original shape of the suffix was obscured, because ${ }^{*} y$ was lost at an early stage with a diverse range of concomitant effects on any preceding consonant, collectively known as palatalisation. ${ }^{7}$

The result of all this is a synchronically rather non-uniform category, and Herodian uses various mechanisms to try to impose a new kind of unity.

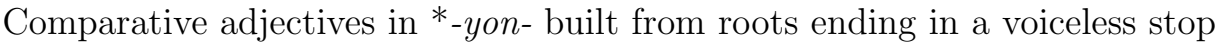
generally yielded forms containing a sequence $-\sigma \sigma_{-} ;^{8}$ so, from the root ${ }^{*} p a k^{h}$ (cf. $\pi \alpha \chi-u-\varsigma$ ), it was possible to form a primary comparative ${ }^{*} p a k^{h}-y \bar{o} n$, which yielded $\pi \alpha \dot{\alpha} \sigma \omega \nu$. On the other hand, comparative adjectives in $*_{-}$yon- built from roots ending in a voiced stop yielded forms containing $-\zeta_{-}$; so, from the

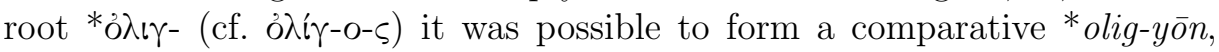
which yielded ỏ $\lambda \hat{\zeta} \zeta \nu$.

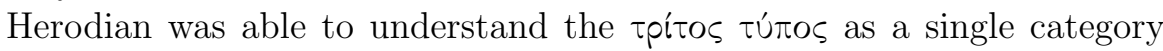

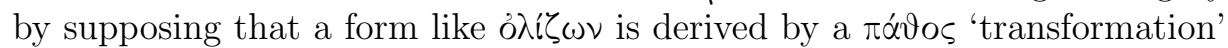
from an intermediate form ỏ $\hat{\imath}^{\circ} \sigma \omega \omega \nu$ which never appears, and was not expected to appear, outside these grammatical contexts; this helps to allow the

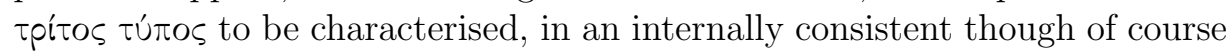
synchronically and diachronically inaccurate fashion, as regularly involving $-\sigma \sigma-.9$

\subsection{The Potential Scope of Herodian's Treatment}

The primary comparatives appear to have been a closed and unproductive class from the time of our earliest Greek texts; their success was not favoured

\footnotetext{
${ }^{6}$ Since Herodian only cites examples with the $n$-stem suffix ${ }^{*}$-yon-, we will confine our remarks to forms with this suffix.

${ }^{7}$ On the phonological outcomes resulting from the loss of $* y$ in Greek, see Lejeune (1972:103-111).

${ }^{8}$ Clusters of a labial stop $+{ }^{*} y$ behave differently, but there are no relevant examples among primary comparatives.

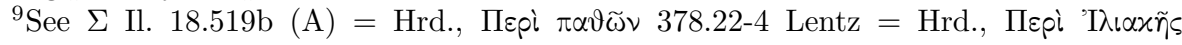

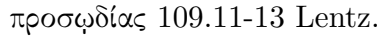


by the morphological opacity caused by palatalisation and the loss of $* y$. So it is easy to enumerate the known examples and assess the scope of the data which Herodian might have attempted to account for. In fact, plausibly Herodianic material in Lentz (1867-70) includes some kind of discussion of every comparative known to be derived with the suffix * ${ }_{-}$yon-: $\alpha$ $\sigma \sigma o \nu, \beta \alpha ́ \sigma \sigma \omega \nu$,

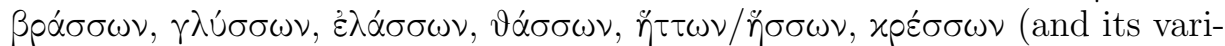

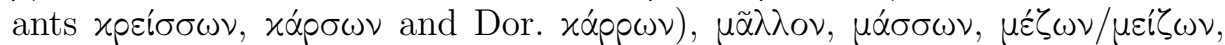

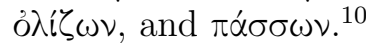

When we come to consider the potential coverage and legitimacy of Herodian's rules on vowel quantity, we should set them in the context of his apparently comprehensive appreciation of the range of comparative forms of this type.

\section{The Passages: Content and Reliability}

A number of parallel Herodianic passages concerning vowel length in comparatives fail to exhibit complete agreement with regard to the organisation of the linguistic material and the distribution of vowel lengths. The manuscript traditions are of varying degrees of reliability and it will prove interesting to consider the extent to which differences of detail might arise from the process of transmission as well as genuine uncertainties or disagreements in antiquity; we should also consider whether in certain cases Herodian, or his successors, might be reworking the material for different purposes.

\subsection{The Subject Matter}

The passages examined here attempt to account for the length of the root vowels in various members of the tpítos tútos of comparative adjectives. Herodian only seems concerned with the length of óxpovos vowels, that is vowels whose length cannot be ascertained from their spelling in the Ionic alphabet (i.e. $\langle\alpha\rangle,\langle\downarrow\rangle$, or $\langle u\rangle$ ). Indeed it would seem redundant to stipulate the length of the root vowel in examples with an orthographically unambiguous long vowel, i.e. $\ddot{\eta} \tau \tau \omega \nu / \ddot{\eta} \sigma \sigma \omega \nu$, or short vowel, i.e. xpé $\sigma \sigma \omega \nu$ or

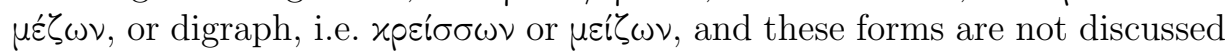
in these passages. However, it is also worth noting that since our material is in most cases mediated by epitomes, whatever the original emphasis in

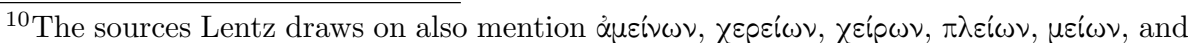
apsí $\omega \nu$, which could involve the suffix *-yon-, but these do not prove important for the questions addressed here.
} 
Herodian's works might have been, they could have been reshaped in the process of epitomizing in accordance with pedagogical requirements.

The forms under consideration are narrowed down further in slightly different ways in different passages, though some of the differences are, in all probability, artefacts of the textual tradition rather than reflecting a diversity in the Herodianic source material. Sometimes, the rules are deemed to apply to comparatives ending in $\Sigma \Sigma \Omega \mathrm{N}$ or $\Sigma \Omega \mathrm{N}$ or A $\Sigma \Sigma \Omega \mathrm{N}$. Another passage picks out comparatives in $\Omega \mathrm{N}$; but this last stipulation seems unlikely to accurately represent the Herodianic position, because the rule as it stands would require one to admit a considerable number of obvious counterexamples. The first three restrictions should each have had the effect of ruling

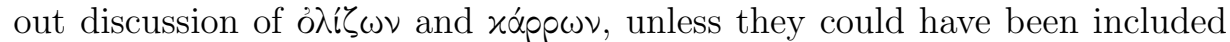
by virtue of theory-internal intermediate forms such as Herodian's ó $\lambda i \sigma \sigma \omega \nu$

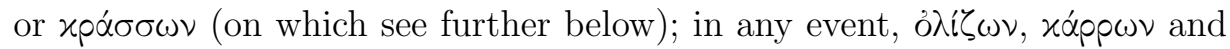
their intermediate forms are not mentioned in any of the relevant passages concerning root vowel length. Stipulations of this kind would, in all likelihood, also exclude $\mu \tilde{\alpha} \lambda \lambda{ }^{\circ} \nu$ from discussion; not only does it not have $-\sigma \sigma-$ or $-\sigma-$, but in addition it only occurs as a neuter adverb and thus does not terminate in a sequence $\Omega \mathrm{N}$ in any context.

\subsection{The Texts: Provenance and Transmission}

Our first text comes down to us in a variety of very similar looking sources. It

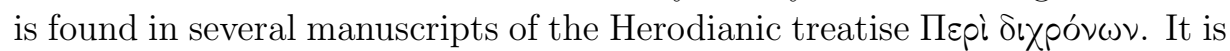
possible that this was not a separate work in the first instance, but rather consists of a thematically defined set of excerpts from book twenty of Herodian's

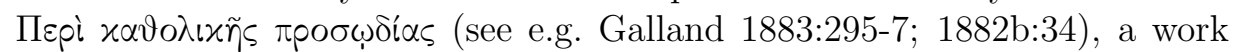
which only survives otherwise in an epitomized form. These manuscripts constitute the principal basis for the text as presented in Lentz' (1867-70) edition.

The same passage was also incorporated into pseudo-Draco Пврi $\mu \varepsilon ́ \tau \rho \omega \nu$

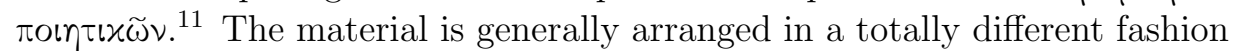

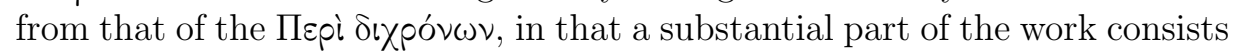
of a (rather approximately) alphabetised series of lemmata, each appearing with information about the length of one of its vowels. But in the lemma dealing with $\gamma \lambda u ́ \sigma \sigma \omega \nu$ there is clear agreement with a passage from the Пврi

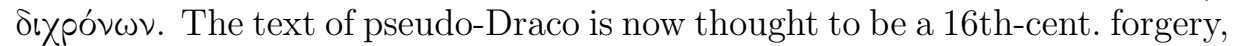
almost entirely assembled from material found in other grammatical works;

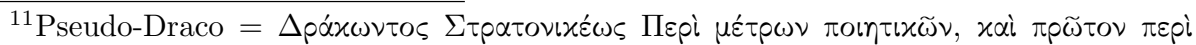

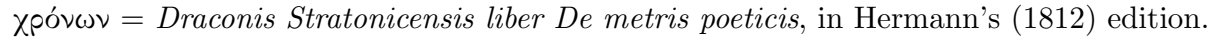


however, its readings may still prove to be of interest, since it is known to draw heavily on Herodianic material. ${ }^{12}$

The same passage is also found in a manuscript reproduced in Hermann (1801) Regulae de Prosodia. One part of this larger work coincides closely

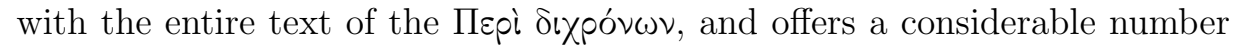
of readings which differ from those in the manuscripts of the Herodianic treatise; Lentz implicitly recognises this as additional source. ${ }^{13}$

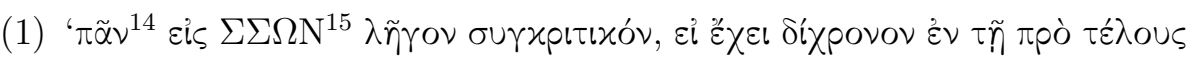

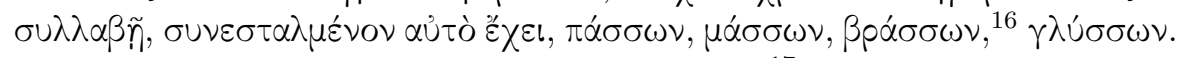

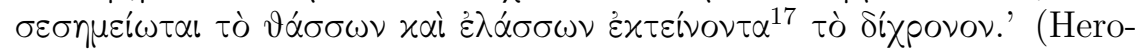

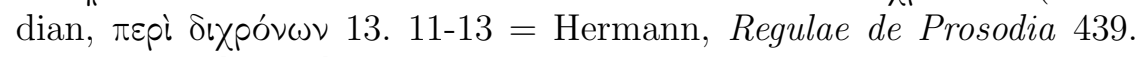
31-440. $2=[$ Draco] 32. 21-25 (s.v. $\gamma \lambda \dot{\sigma} \sigma \sigma \omega \nu)$

'Every comparative ending in $-\sigma \sigma \omega \nu$, if it has a vowel of ambiguous length in its penultimate syllable, has this vowel short: $\pi \alpha \dot{\sigma} \sigma \omega \nu$, $\mu \alpha \dot{\sigma} \sigma \omega \nu, \beta p \alpha ́ \sigma \sigma \omega \nu, \gamma \lambda \cup ́ \sigma \sigma \omega \nu$. The words $\vartheta \dot{\alpha} \sigma \sigma \omega \nu$ and $\dot{\varepsilon} \lambda \alpha \dot{\alpha} \sigma \sigma \omega \nu$ are exceptions, having their length-ambiguous vowels long.'

Most of the manuscript divergences are either a simple matter to resolve, or do not create serious difficulties of interpretation. But there is one important point at issue. In the codices which Lentz' edition of the Пврi

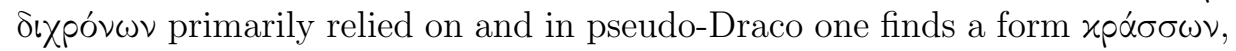
but the manuscript which provides the basis for Hermann's (1801) text gives ßpá $\sigma \sigma \omega \nu$. Even though pseudo-Draco is thought to be a forgery, it was clearly based on Herodianic material and the author seems to have had access to manuscripts with the reading xpá $\sigma \sigma \omega \nu$.

\footnotetext{
${ }^{12}$ See Hunger (1978:52-3). Doubts about the authenticity of the purported text of Draco were raised from a very early stage; even in the preface to Hermann's (1812) edition, striking correspondences with the work of Laskaris were noticed. That this text is assembled from other grammatical works was shown by Lehrs (1857:402-415) and some of the material that Lehrs was unable to attribute has since been identified, see Cohn (1888:134 and footnote 1). The creator of this work has been identified as the scribe of pseudo-Philemon (see Pulch 1882:183-4 and Cohn 1888:134-5) and manuscript C of pseudo-Arcadius's epitome of

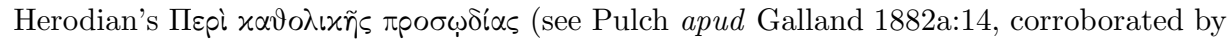
Omont apud Cohn 1888:141), on the basis of a comparison of scribal hands. He is believed to be Jakob Diassorinos, who worked in the royal library at Fontainebleau during the reign of Henry II of France in the mid-16th cent., see Gamillscheg and Harlfinger (1981:89-90 and 1989:85-86) and Cohn (1888:133-43).

${ }^{13}$ See Lentz (1867-70:i.lxxii).

${ }^{14} \pi \tilde{\alpha} \nu$ rà $[$ Draco]

${ }^{15}$ ov regg. Herm., $\Sigma \Omega \mathrm{N}$ [Draco]

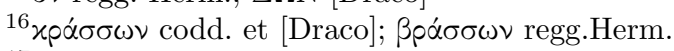

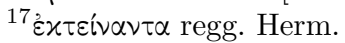


A form like $x \rho \alpha ́ \sigma \sigma \omega \nu$ would not be an implausible comparative adjective for Greek. We find the root ${ }^{*} k r a t-(<* k r t-)$ in xpatús and so one could suppose $x p \alpha ́ \sigma \sigma \omega \nu<* k r a t-y \bar{o} n<* k r t-y \bar{o} n$. However, as it happens, xpá $\sigma \sigma \omega \nu$ does not occur outside grammatical works and in all other contexts apart from this $x p \alpha ́ \sigma \sigma \omega \nu$ is only given as an intermediate form in a derivational procedure, as in e.g. Hrd., Пвpi $\pi \alpha \vartheta \widetilde{\omega \nu ~(383.13-27), ~ w h e r e ~ i t ~ f o r m s ~ a n ~ i n t e r-~}$ mediate step in explaining the comparative xáppov; in the same passage of the $\Pi \varepsilon p i \tau i \alpha \vartheta \widetilde{\omega} \nu$, and in the same spirit, we find $\tau \alpha \dot{\alpha} \sigma \sigma \omega \nu$ as an intermediate step in the formation of $\vartheta \alpha \dot{\sigma} \sigma \sigma \omega \nu$, though there is no implication that $\tau \dot{\alpha} \sigma \sigma \omega \nu$ could ever itself be used in Greek.

Given the availability of the plausible alternative reading $\beta \rho \alpha ́ \sigma \sigma \omega \nu$ in regg. Herm, and given that $\beta p \alpha ́ \sigma \sigma \omega \nu$ is found in a parallel passage (passage 2 below), we should not take the reading $x p \alpha ́ \sigma \sigma \omega \nu$ too seriously; the manuscript variants are easy to understand given the very common confusion of $\langle\beta\rangle$ and $<x>$ in minuscule script.

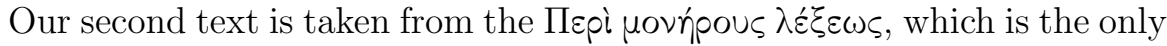
more or less complete work of Herodian which we possess. The text given here is that of Lentz (1867-70), though he reproduces Lehrs' (1848:129) text without substantive changes:

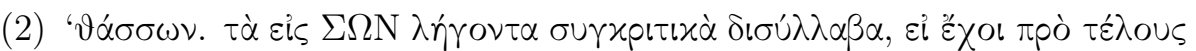

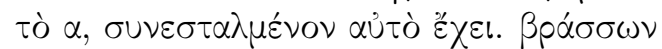

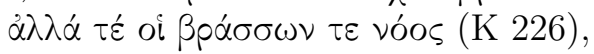
$\pi \dot{\alpha} \sigma \sigma \omega \nu$

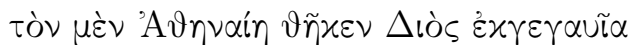

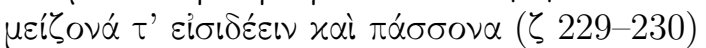

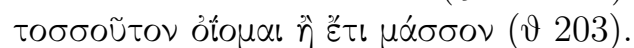

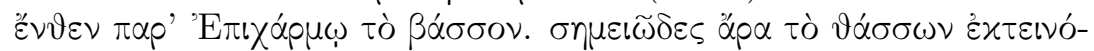

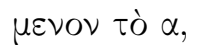

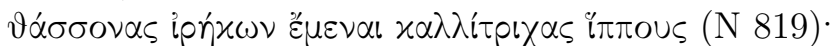

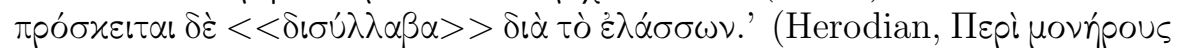

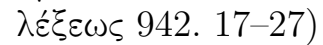

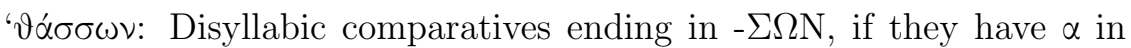
the penultimate syllable, have it short:

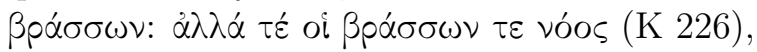

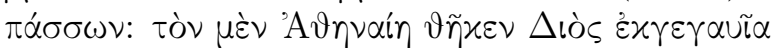

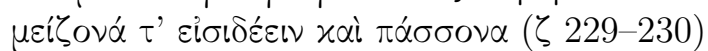

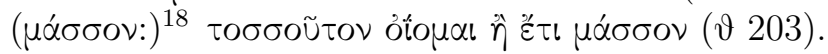

\footnotetext{
${ }^{18}$ It seems clear, from the overall structure of this passage and the contents of the following Homeric quotation, that an entry $\mu \alpha \dot{\sigma} \sigma \sigma \nu$ or $\mu \alpha \dot{\alpha} \sigma \omega \nu \nu$ ought to be supplied here.
} 


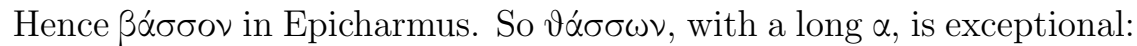

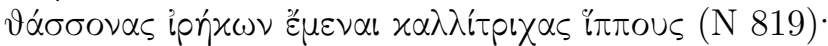

And the word "disyllabic" is included because of $\dot{\lambda} \lambda \alpha \sigma \sigma \omega \nu$.

Because this work is concerned with uovñpn 'solitary, unique, or singular' words, the rule is formulated so as to be all about $\vartheta \alpha \dot{\alpha} \sigma \sigma \omega \nu$ (one of the two exceptions to the more general rule in passage 1). ${ }^{19}$ In order that $\vartheta \alpha \dot{\sigma} \sigma \sigma \omega \nu$ could be construed as a unique example with a long root vowel, an additional stipulation limits the rule to disyllabic forms, thus explicitly excluding $\varepsilon \lambda \lambda \alpha ́ \sigma \sigma \omega \nu$ from consideration.

So passages (1) and (2) agree in assigning a short $a$-vowel to $\pi \dot{\alpha} \sigma \sigma \omega \nu$, $\mu \alpha \dot{\sigma} \sigma \sigma \omega \nu$, and $\beta p \alpha ́ \sigma \sigma \omega \nu$ and a long $\bar{a}$-vowel to $\vartheta \alpha \dot{\sigma} \sigma \sigma \omega \nu$ and $\dot{\varepsilon} \lambda \dot{\alpha} \sigma \sigma \omega \nu$. Only passage (2) mentions a short $a$-vowel in $\beta \alpha ́ \sigma \sigma \omega \nu$, and only passage (1) mentions a short $u$-vowel in $\gamma \lambda \dot{v} \sigma \sigma \omega \nu$, because in passage (2) only examples with an $a$-vowel in the penultimate syllable are considered, rather than sixpovos vowels more generally.

Passage (3) derives from pseudo-Arcadius's epitome of the twentieth book

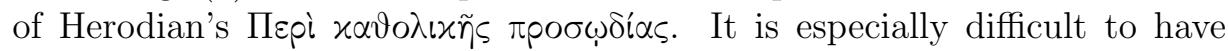
any confidence in our knowledge of this part of Herodian's work, because it is preserved only in the epitome of pseudo-Arcadius and, furthermore, this part of the epitome is only continued in one manuscript out of the five which are extant (Manuscript C: Parisinus 2102). Furthermore, this is a derivative manuscript, going back to a source which did not contain book twenty (see Roussou 2011:107-11). Galland (1882a:17-18) argued, on the basis of the pattern of preservation, content and phraseology, that this book did not come down to us from antiquity, but was compiled more recently from a number of other sources. ${ }^{20}$ This suspicion is strengthened by the fact

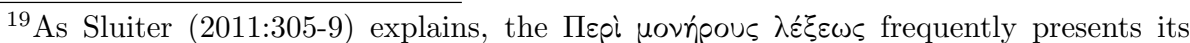
examples as being unique in the sense that they are subject to a grammatical rule which has scope over only one word. Its rules are often of the form "no $\mathrm{x}$ is $\mathrm{y}$ except the word under discussion'. But traces of the usual pattern also surface, whereby the most general properties of the grammar are stated before listing exceptions; the rule in passage (2) is such an example: $\vartheta \alpha ́ \sigma \sigma \omega \nu$ is made to be a unique exception to a general rule, rather than a unique example conforming to a rule with scope over just one word.

${ }^{20}$ Dyck (1993:778-9), citing Galland (1882a:17-18), says that book 20 of the epitome of pseudo-Arcadius was compiled from "known sources". But this claim seems too strong;

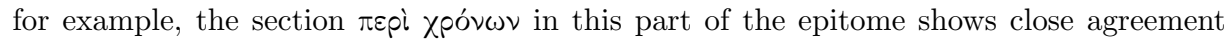
in rules, ordering, and examples with the second of the probably Byzantine compilations

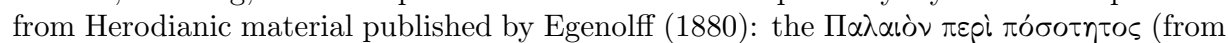
which our passage (5) is drawn), see Galland (1882b:33-34 and 1883:298). Furthermore, there is a close correspondence in forms and sequence between clusters of illustrative examples used in both of these works and various sequences of lemmata in the $\Lambda \varepsilon \xi_{\text {c }}$ xòv

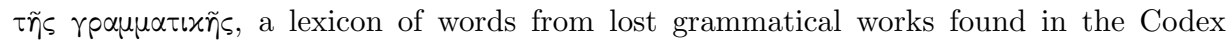


that manuscript $\mathrm{C}$ is in the hand of Jacob Diassorinus, the 16th-cent. scribe now thought to be responsible for forging the text of pseudo-Draco, which also contains similar subject matter (see footnote 12). Nevertheless, on the grounds that this text very probably draws heavily on Herodianic material, it is worthwhile to consider its testimony:

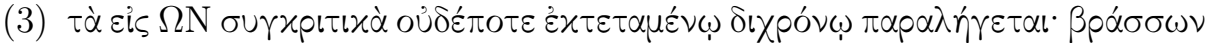

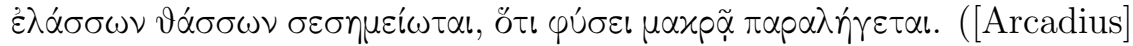
220. 6-8 Schmidt $)^{21}$

'Comparatives in $\Omega \mathrm{N}$ never have a length-ambiguous vowel which is

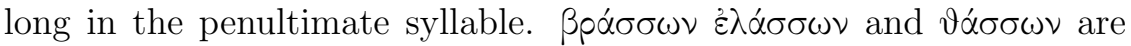
exceptions, since they have a vowel long by nature in the penultimate syllable.'

As Lehrs (1848:129 footnote 37, 3) notes, it is difficult to understand this rule if we truly take it to apply to all comparatives in $\Omega N$. Such a broad

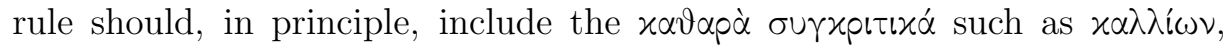
$\dot{\eta} \delta i \omega v$, etc., which Herodian reports as having a long vowel in the penultimate

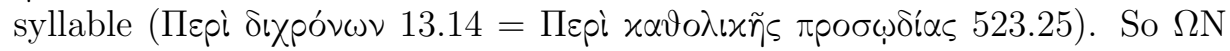
should probably be emended to $\Sigma \Omega \mathrm{N}$ or $\Sigma \Sigma \Omega \mathrm{N}$.

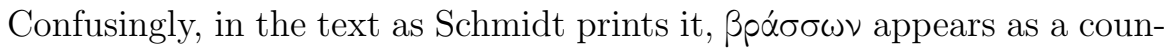
terexample to the general rule, and is reported to have a long root vowel. This contradicts the information given in passages (1) and (2). It is, of course, possible that the passage is corrupt or spurious. It is even possible that Herodian's doctrine was not completely consistent, or that this passage represents another school of thought. But the most likely explanation is that the punctuation of Schmidt's text is incorrect. In all the other parallel passages considered here, it will become clear that when a rule is put forward, at least one example of that rule is given before any counterexamples are offered. With Schmidt's punctuation we have to assume that no example of

Coislinianus 345 and published by Bachmann (1828:425-50), see Galland (1882b:31-2 and 1882a:18). It seems clear from the correspondences and from the occurrence of examples or rules in each work which do not appear in the others, that none of these three works was the source for the others and that they drew on a common source. Considerations of content and ordering suggest that this source was probably not the twentieth book of the

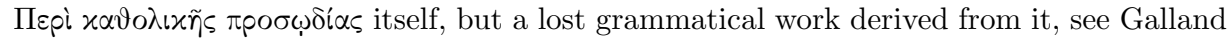
(1882b:31-4).

${ }^{21}$ Here we follow Schmidt's (1860) edition rather than Lentz (1867-70), who reconstructs the text at this point based on the epitome with supplements from other similar passages in

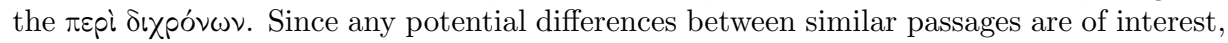
such reconstructions are not helpful in this context. 
the general rule is given. On the other hand, if one punctuates after $\beta p \alpha ́ \sigma \sigma \omega \nu$ instead, then we may translate as follows: ${ }^{22}$

'Comparatives in $\Omega \mathrm{N}$ never have their length-ambiguous vowel long

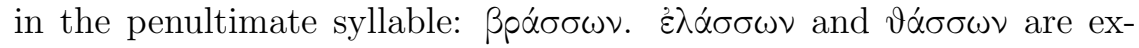
ceptions, since they have a vowel long by nature in the penultimate syllable.'

Passages (4) and (5) were not known to Lentz (1867-70) when he compiled his edition, but were published by Egenolff (1880). These consist of two

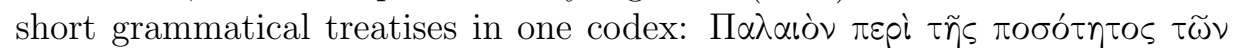

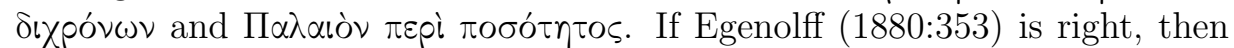
these probably represent Byzantine compilations from Herodianic material, which by no means rules them out as possible evidence on these matters. ${ }^{23}$

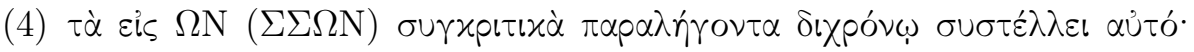

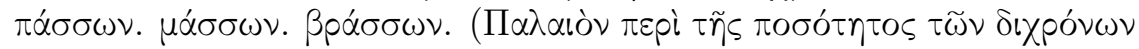
in Egenolff 1880, 357. 19-20)

'Comparatives in $-\omega \nu$ (i.e. $-\sigma \sigma \omega \nu$ ) with a vowel of ambiguous length in

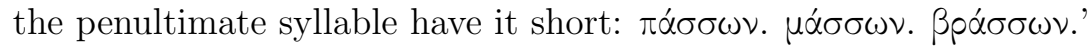

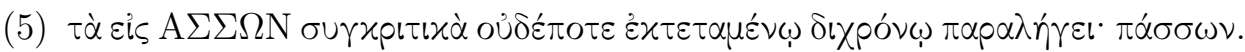

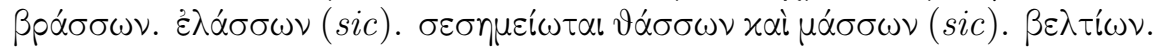

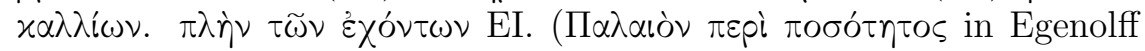
1880, 361. 30-32)

'Comparatives in $-\alpha \sigma \sigma \omega \nu$ never have a length-ambiguous vowel which is long in the penultimate syllable: $\pi \dot{\alpha} \sigma \sigma \omega \nu, \beta p \alpha ́ \sigma \sigma \omega \nu, \dot{\varepsilon} \lambda \alpha \dot{\alpha} \sigma \sigma \omega \nu$ (sic). $\vartheta \alpha ́ \sigma \sigma \omega \nu$ and $\mu \alpha ́ \sigma \sigma \omega \nu$ (sic) are exceptions. $\beta \varepsilon \lambda \tau i \omega \nu, ~ \varkappa \alpha \lambda \lambda i \omega \nu$. Apart from those with -عเ-.'

Passage (4) seems relatively straightforward in the light of what we have seen already, except for the obvious fact that it does not mention any exceptions to the rule, and if we read $\Omega \mathrm{N}$ rather than $\Sigma \Sigma \Omega \mathrm{N}$, then a great many further counterexamples would have to be admitted. But passage (5)

\footnotetext{
${ }^{22}$ I am very grateful to Dr Philomen Probert for bringing this punctuation problem to my attention and for suggesting the solution. For a recognition of the problem presented by this passage and a solution along similar lines but with a greater degree of emendation, see Lehrs (1848:129 footnote 37, 3). For a parallel example of the asyndeton produced by this emendation and for a parallel example of a list with a single member, cf. [Arcadius] 224.12-14 Schmidt.

${ }^{23}$ See above and also see Galland $(1883: 298)$ on the Herodianic origins of this material.
} 
presents serious difficulties both in its own terms and in terms of what we have seen elsewhere. In this passage, $\dot{\varepsilon} \lambda \dot{\alpha} \sigma \sigma \omega \nu$ is deemed to have a short vowel, while $\vartheta \alpha ́ \sigma \sigma \omega \nu$ and $\mu \alpha \dot{\sigma} \sigma \sigma \omega \nu$ are identified as exceptions to the general rule, having long root-vowels. But in the other passages $\dot{\lambda} \lambda \alpha \sigma \sigma \sigma \omega \nu$ was said to have a long root-vowel and $\mu \alpha \dot{\sigma} \sigma \omega \nu$ a short vowel.

The question of the appropriate vowel length for $\mu \alpha \dot{\sigma} \sigma \sigma \omega \nu$ is not an entirely straightforward matter, because we find some examples of the neuter singular of this form with a circumflex on the root syllable: $\mu \tilde{\alpha} \sigma \sigma o v$ (e.g. in manuscripts of A. Pr. 629). This is a question to which we will return presently, but the contribution made by this text can only be very limited, because a number of other inconsistencies make it highly likely that this whole passage is corrupt. It is completely unclear why $\beta \varepsilon \lambda \tau i(\omega \nu$ and $x \alpha \lambda \lambda i \omega \nu$ figure in this rule at all, because they do not meet the criteria for inclusion.

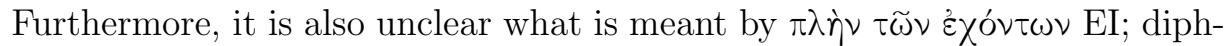
thongs are not dixpovos vowels and no rule is needed to establish their length. It looks as if there may have been a conflation of more than one passage by a scribe who did not understand what he was copying. The testimony of this passage can only be used with great caution.

\subsection{The Herodianic Position}

We have seen that the history of the texts containing these passages is fraught with difficulties. But there is a real possibility that many of our texts reflect, in different ways and in an indirect fashion, part of the text of the lost

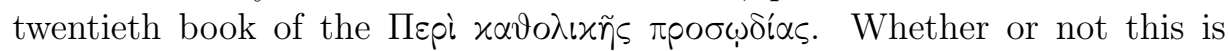
indeed the case, there is a good measure of agreement on many points, and it does not seem difficult to reach a conclusion regarding the likely Herodianic doctrine on these vowel lengths.

According to all five passages ßpá $\sigma \omega \nu$ has a short root vowel, provided that we emend the punctuation of passage (3) and provided that we accept

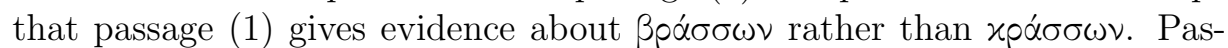
sages (1), (2), (4), and (5) attest to a short vowel in $\pi \dot{\alpha} \sigma \sigma \omega \nu$. According to passage (1) $\gamma \lambda \cup ́ \sigma \sigma \omega \nu$ has a short root vowel. Passage (2) attests to a short

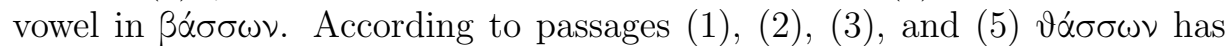
a long root vowel. The evidence of the various passages is consistent with regard to these points.

The only real points of disagreement arise in the case of $\mu \alpha \dot{\sigma} \sigma \sigma \omega \nu$ and $\varepsilon \dot{\varepsilon} \alpha \dot{\sigma} \sigma \sigma \omega \nu$. According to passages (1), (2), and (4) $\mu \alpha \dot{\sigma} \sigma \sigma \omega \nu$ has a short root vowel, but passage (5) alone speaks for a long vowel. According to passages (1), (2), and (3) $\dot{\varepsilon} \lambda \dot{\alpha} \sigma \sigma \omega \nu$ has a long root vowel, but passage (5) alone speaks for a short vowel. 
So if we accept that passage (5) is corrupt and if we can safely disregard it, then all the reliable evidence points towards a short root vowel in $\pi \alpha \dot{\sigma} \sigma \sigma \omega \nu$,

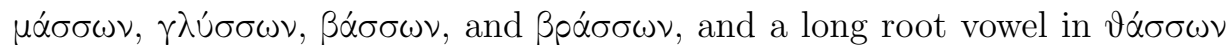
and $\dot{\varepsilon} \lambda \dot{\alpha} \sigma \sigma \omega \nu$. It now remains for us to try to establish whether there is any linguistic basis for what appears to be the Herodianic position.

\section{Herodianic Doctrine in a Wider Context}

The evidence of the Herodianic material is not always in agreement with other sources of evidence for vowel length in Greek, and such mismatches call for an explanation. Herodian's evidence also raises some significant etymological problems, particularly when it comes to understanding why any of these forms should have a long vowel.

\subsection{Unproblematical Examples}

It is a relatively straightforward matter to account for the short root-vowels in $\pi \alpha \dot{\sigma} \sigma \omega \nu, \gamma \lambda \dot{u} \sigma \sigma \omega \nu, \beta \alpha ́ \sigma \sigma \omega \nu$, and $\beta \rho \alpha ́ \sigma \sigma \omega \nu$ : they go back to forms containing the roots $p \breve{a} k^{h}-\left(<^{*} p n k^{h}\right.$, cf. $\pi \alpha \times u^{\prime} s$ and perhaps Ved. bahú- $<* b^{h} n g^{h}-$ and/or

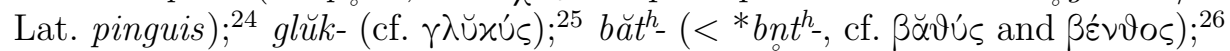

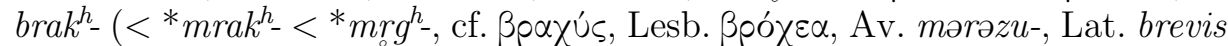
$<{ }^{*}$ mre $\hat{g}^{h} w$-i-, etc.). ${ }^{27}$ In these cases, Herodian's testimony agrees with our etymological expectations.

\subsection{Conflicting Evidence: $\mu \alpha \dot{\alpha} \sigma \omega \nu$}

The testimony of the Herodianic passages for a short root vowel in $\mu \alpha \dot{\alpha} \sigma \omega \nu$ accords well with comparative evidence for a root ${ }^{*} m a \breve{k}$ - (cf. Lat. macer 'meager, thin', OHG magar, Hitt. mak-l-ant- 'thin'). However, a long root vowel seems to be demanded by the evidence for the accent of the neuter singular $\mu \tilde{\alpha} \sigma \sigma o v$. It is interesting to find such an obvious divergence between the accentual tradition and the position taken by Herodian.

\footnotetext{
${ }^{24}$ For etymological difficulties in relating these forms, see Lamberterie (1990:95-6; 99101) and Seiler (1950:40-41).

${ }^{25}$ Perhaps compare also Lat. dulcis if both can be derived from *dlukus, see Beekes (2010:277-8).

${ }^{26}$ On the idea that there was instead a connection with $\beta \tilde{\eta} \sigma \sigma \alpha$ 'glen', see Chantraine (1999:155-6) with bibliography, but for arguments generally supportive of the connection

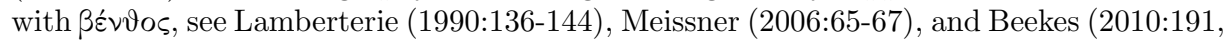
212-3 s.v. $\beta \tilde{\eta} \sigma \sigma \alpha)$.

${ }^{27}$ See Lamberterie (1990:156-163).
} 
The possible origins of this putative long $\bar{a}$-vowel will be considered presently, but it is clear that it cannot be very old. We find $\mu \alpha \dot{\alpha} \sigma \sigma \omega \nu$ in Ionic, but an original long $* \bar{a}$ would have been replaced by $/ \bar{e} /$ in this dialect, as we see, for example, in the cognate $\mu \tilde{\eta}$ xos $<{ }^{*} m \bar{a} k o s\left(<{ }^{*} m e H_{2} \hat{k}-o-s\right)$ and $\mu \dot{n} x เ \sigma \tau о \varsigma<{ }^{*} m \bar{a} k i s t o s\left(<{ }^{*} m e H_{2} \hat{k}\right.$-isto-s). This old long vowel clearly cannot be responsible for the root vowel of $\mu \tilde{\alpha} \sigma \sigma o v$.

\subsection{Etymological Difficulties: $\vartheta \dot{\alpha} \sigma \sigma \omega \nu$}

The long root vowel attributed to $\vartheta \alpha \dot{\alpha} \sigma \sigma \omega \nu$ by Herodian is consistent with the circumflex accent found in the neuter singular $\vartheta \tilde{\alpha} \sigma \sigma o v$, but difficult to understand from an etymological perspective. If the $\bar{a}$-vowel is old, it is unclear why it did not undergo the Attic-Ionic change of long $* \bar{a}$ to $/ \bar{e} /$. If the long $\bar{a}$-vowel arose later, then the mechanism is somewhat unclear.

The cognate positive adjective is $\tau \breve{\alpha} \chi \mathcal{u}^{\prime} \varsigma<* t^{h h} a k^{h}-u-s$, where the word initial stop has undergone the regular dissimilation of the first of two aspirates in successive syllables (Grassmann's Law). ${ }^{28}$ The root initial aspirate is retained in $\vartheta \alpha \dot{\sigma} \sigma \sigma \omega \nu$, because the addition of the *-yon-suffix deaspirated the root final consonant at an earlier stage, i.e. $\vartheta \dot{\alpha} \sigma \sigma \omega \nu<{ }^{*} t^{h} \bar{a} k-y o n-<* t^{h} \breve{a} k^{k h}-y o n-$.

Seiler (1950:40) argued for a comparative ${ }^{*} t^{h} \bar{a} k^{h}-y o n-$ whose $* \bar{a}$ did indeed develop to ${ }^{*} \bar{e}$, giving ${ }^{*} t^{h} \bar{e} s s \bar{o} n$, with subsequent remodelling of the quality, though not the length, of the root vowel on the model of $\tau \alpha \times \dot{v}^{\prime}$, i.e. ${ }^{*} t^{h} \bar{e} s s \bar{o} n$ $\rightarrow \vartheta \bar{\alpha} \sigma \sigma \omega \nu$. But this is not particularly convincing: if the link with $\tau \alpha \chi u^{\prime} \varsigma$ was the motivating factor, then it is unclear why the word initial consonant in $\vartheta \bar{\alpha} \sigma \sigma \omega \nu$ was not also remodelled.

One might try to argue that long ${ }^{*} \bar{a}$ in the root arose by regular sound change within the history of Greek, and to this end entertain an etymological connection with the root of Lith. danginti-s 'set off somewhere', reconstructing for Greek ${ }^{*} d^{h} a n g^{h}-y o n->{ }^{*} t^{h} a n k^{h}-$ yon- $>{ }^{*} t^{h}$ ansson- $>{ }^{*} t^{h} \bar{a} s s o n-$, with loss of the nasal before ${ }^{*} s$ and compensatory lengthening of the preceding vowel, after the Attic-Ionic change of $* \bar{a}>/ \bar{e} /$ was complete.

However, an explanation of this kind is unsatisfactory for several reasons. We lack an independent parallel for the proposed change. If we assumed that a sequence ${ }^{*}$ nasal + velar stop $+{ }^{*} y$ behaved in the same way as a sequence ${ }^{*}$ nasal + dental stop $+{ }^{*} y$, then we would have expected an outcome ${ }^{*} t^{h} \bar{a} s \bar{o} n$ rather than $\vartheta \bar{\alpha} \sigma \sigma \omega \nu$, cf. the feminine nominative singular * pant-ya $>\pi \tilde{\alpha} \sigma \alpha$ 'all' in both Attic and Ionic. On the other hand, if velars behaved differently from dentals in this environment, as indeed they do in most other

\footnotetext{
${ }^{28}$ The ultimate etymology is far from established, see Lamberterie (1990:584-590) for some possibilities.
} 
contexts, then in Attic we would usually expect a development ${ }^{*}-k^{(h)} y->-\tau \tau-$, yielding $* t^{h} a n t t \bar{o} n$ or $* t^{h} a n t \bar{o} n$ instead of $\vartheta \dot{\alpha} \tau \tau \omega \nu$, because, other than before a sibilant, we would usually expect a preconsonantal nasal to be preserved. Furthermore, even in dialects like Ionic, where $*-k^{h} y$ - would regularly yield a sibilant, it seems likely that a sequence ${ }^{*}-V n k^{h} y$ - would have yielded single *-s- rather than a geminate, even leaving aside any potential parallel with $\pi \tilde{\alpha} \sigma \alpha$ : it is probable that the sequence would have been syllabified as *$V n . k^{h} y$ - (if onsets were maximised), and in Greek we never find a geminate outcome from $*$ stop $+* y$ clusters in a syllable onset. ${ }^{29}$

So the development of a long vowel by compensatory lengthening in $\vartheta \alpha \dot{\sigma} \sigma \omega \nu$ seems to be inconsistent with its geminate $-\sigma \sigma-$. We shall see presently that a better understanding of this phenomenon can be reached by considering it in a slightly wider context.

\subsection{Etymological Difficuties: $\dot{\varepsilon} \lambda \alpha \dot{\sigma} \sigma \omega \nu$}

Questions of the same kind surround $\dot{\varepsilon} \lambda \dot{\alpha} \sigma \sigma \omega \nu$. The root must have origi-

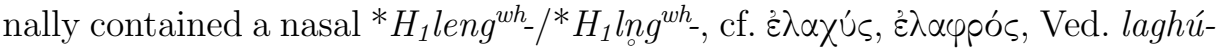

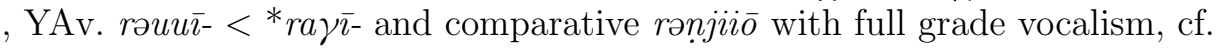
Lith. lẽngvas. ${ }^{30}$ Even if one assumed that a form ${ }^{*}$ elank ${ }^{h}$-yon- could have arisen through interference between full grade and zero grade root shapes

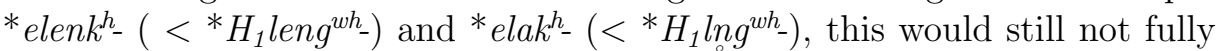
explain the outcome Ion. $\dot{\varepsilon} \lambda \dot{\alpha} \sigma \sigma \omega \nu$ / Att. $\dot{\varepsilon} \lambda \dot{\alpha} \tau \tau \omega \nu$ for the same reasons that an intermediate form ${ }^{*} t^{h} a n k^{h}$-yos- cannot easily explain $\vartheta \dot{\alpha} \sigma \sigma \omega \nu / \vartheta \dot{\alpha} \tau \tau \omega \nu$.

\subsection{A Notable Omission}

Herodianic sources omit to mention the length of root vowels in a number of comparative formations. In part this arises from the rather tight definition of the categories which he planned to address. For example, the length of the root vowel in $\mu \tilde{\alpha} \lambda \lambda$ ov is not discussed along with those of the other comparatives. ${ }^{31}$ This could simply be due to the fact that it did not have a stem in $\Sigma(\Sigma) \Omega \mathrm{N}$. But this explanation would not apply to $\alpha$ $\sigma \sigma o v$ 'near'-a form found in poetry and Ionic prose, e.g. Hom., Hdt., Ar., S., etc.

\footnotetext{
${ }^{29}$ Compare the word initial $* k y$ - or $t y$ - sequences which yield simplex $\sigma$ - or $\tau$ - in all

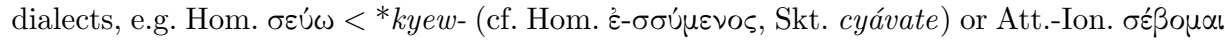

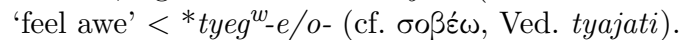

${ }^{30}$ For a full discussion of the cognates, see Lamberterie (1990:183-6).

${ }^{31}$ Note, however, the interesting discussion of the length and quality of the root vowel

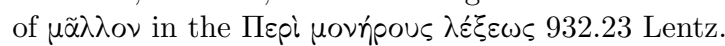


In historical terms, $\check{\sigma} \sigma \sigma \mathrm{v}$ was a comparative adjective related to the adverb 'a $\gamma \times \iota$ 'near', and there are solid etymological grounds for supposing that the root vowel was long (see Seiler 1950:45-6, and Peters 1980:288). Its absence from Herodian's discussion alongside $\vartheta \dot{\alpha} \sigma \sigma \omega \nu$ and $\dot{\varepsilon} \lambda \alpha \dot{\sigma} \sigma \sigma \nu \nu$ might seem surprising given that it has a stem ending in $-\sigma \sigma-$.

However, it is pretty clear that $\tilde{\sigma} \sigma \sigma o v$ stopped being analyzable as a comparative at a prehistoric stage. Already in Homer and Aeschylus innovative comparative and superlative formations, $\dot{\alpha} \sigma \sigma o ́ \tau \varepsilon \rho o \varsigma$ and $\alpha$ $\sigma \sigma \iota \tau \tau$, were built directly upon the stem of $\check{\sigma} \sigma \sigma o \nu$, as if it were a positive form itself rather than comparative. It seems more or less certain that Greek inherited a $u$ stem adjective built from this same root (cf. Ved. amhú-, Sl. azъ ks, Goth. aggwus, OIr. cumung and probably Arm. anjuk, see Lamberterie 1990:265270). It was probably lost only a short while before Homer (as suggested

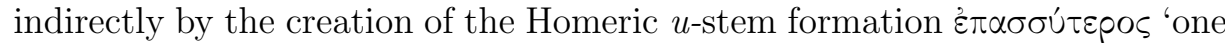
upon another'). Once the $u$-stem positive adjective was lost, at a prehistoric stage, $\check{\sigma} \sigma \sigma o v$ was isolated and effectively became a positive, unanalyzed form from which other analogical formations could be built.

\section{Reconciling etymology and tradition}

We have seen that in most instances, Herodian's doctrines on the length of

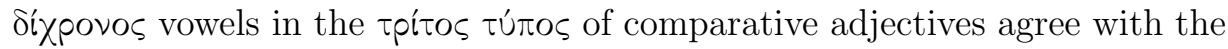
results of etymological enquiry: Herodian reports $\pi \alpha ́ \sigma \sigma \omega \nu, \gamma \lambda \dot{\sigma} \sigma \sigma \omega \nu, \beta \alpha ́ \sigma \sigma \omega \nu$, $\beta p \alpha ́ \sigma \sigma \omega \nu$, and $\mu \alpha \dot{\sigma} \sigma \sigma \omega \nu$ as having short root vowels and this conforms with

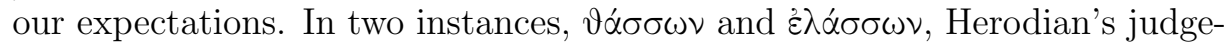
ments and our etymologies are in conflict. In one case, $\mu \alpha \dot{\sigma} \sigma \omega \nu$, Herodian's judgement and our etymologies agree, but they disagree with the tradition of accentuation which perpetuates $\mu \tilde{\alpha} \sigma \sigma o v$.

\subsection{Explaining long root vowels}

We have seen that it is difficult to find an etymological justification for the long root vowel in $\vartheta \bar{\alpha} \sigma \sigma \omega \nu$ and $\dot{\varepsilon} \lambda \bar{\alpha} \sigma \sigma \omega \nu$ reported by Herodian, and that whatever its origin, it must post-date the change of Attic-Ionic $* \bar{a}$ to $/ \bar{e} /$.

There is a dialect which shows a regular process of vowel lengthening in comparative formations: in Attic we find primary comparatives such as

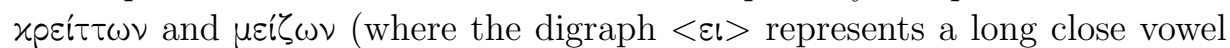

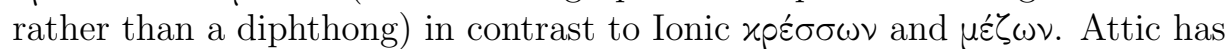
comparatives with $-\bar{t} \omega \nu$ where Homer only has $-\grave{L} \omega \nu$ (see Seiler 1950:15-16). It 
seems that the syllable before $-\omega \nu$ in this formation regularly gets lengthened in Attic. ${ }^{32}$

Furthermore, Wackernagel (1914:124) already noticed that Herodian categorises as having long root vowels precisely those comparatives which had a corresponding form in Attic; we find endless examples of $\dot{\imath} \lambda \alpha \dot{\tau} \tau \omega \nu$ in Attic and $\vartheta \alpha ́ \tau \tau \omega \nu$ also occurs in Attic literature, though with less frequency. On the other hand, forms identified as having short root vowels lack a corresponding form in Attic. While $\pi \dot{\alpha} \sigma \sigma \omega \nu$ occurs several times in Homer, Archilochus, and Theocritus, we never find an Attic form ${ }^{*} \pi \dot{\alpha} \tau \tau \omega \nu$, and while $\mu \alpha \dot{\alpha} \sigma \sigma \omega \nu$ is found in Pindar, Aeschylus and other poetic texts, as well as in Xenephon, we never find $* \mu \dot{\alpha} \tau \tau \omega \nu$. We only find $\beta p \alpha ́ \sigma \sigma \omega \nu$ in Homer (Il.10.226) and grammarians, there is no form ${ }^{*} \beta \rho \dot{\alpha} \tau \tau \omega \nu ; \gamma \lambda \dot{v} \sigma \sigma \omega \nu$ is only attested in a fragment of Xenophanes, indeed a fragment which is only preserved in one of the passages of Herodian under discussion; it is never found again and there is certainly no form * $\gamma \lambda \hat{\cup} \tau \tau \omega \nu$. We find $\beta \alpha ́ \sigma \sigma \omega \nu$ in a fragment of Epicharmus but there is no form * ${ }^{*} \dot{\alpha} \tau \tau \omega \nu$.

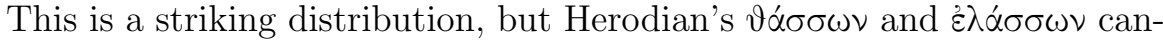
not be attributed directly to Attic in any straightforward way, because instead of $-\tau \tau$ - the forms cited have $-\sigma \sigma-$, which one might assume to represent the state of affairs in Ionic or Homeric Greek, where lengthening is not expected.

\subsection{Sources for Herodian's linguistic judgements}

In these examples, Herodian appears to be reporting a combination of Attic root vowel quantities and the Ionic outcomes of palatalisation. This combination of characteristic features of both Attic and Ionic is reminiscent of the linguistic situation which we find in the Koiné. In light of the way in which Attic Greek fed into later forms of the language, it does not seem at all implausible to suppose that $\vartheta \bar{\alpha} \sigma \sigma \omega \nu$ and $\dot{\varepsilon} \lambda \bar{\alpha} \sigma \sigma \omega \nu$ could be Koiné forms based on Attic $\vartheta \bar{\alpha} \tau \tau \omega \nu$ and $\dot{\varepsilon} \lambda \dot{\alpha} \tau \tau \omega \nu$. During the formation of the Koiné, Attic forms very readily gave up their double $-\tau \tau$ - and we find a complete mixture of forms with $-\sigma \sigma-$ and $-\tau \tau$ - in inscriptions and papyri right down to the Roman period. Indeed precisely such a mixture of features is what

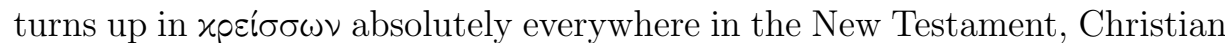
writings, and other Koiné texts, as well as in late Attic inscriptions. This

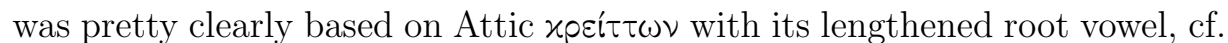
Ion. xpé $\sigma \sigma \omega \nu$, but with the substitution of $-\sigma \sigma-$ in place of original $-\tau \tau-$.

\footnotetext{
${ }^{32}$ For the idea that this lengthening was a uniquely Attic phonological change, see Lagercrantz (1898:36). But an analogical solution seems more likely, given the categoryrestricted nature of the change, see Kuryłowicz (1956:275-6).
} 
Thus Herodian might be accurately reporting a combination of linguistic features characteristic of the Koiné rather than Ionic or Homer. Certainly $\vartheta \dot{\alpha} \sigma \sigma \omega \nu$ and $\dot{\varepsilon} \lambda \alpha \dot{\sigma} \sigma \sigma \omega \nu$ are attested in Koiné texts, though we cannot know

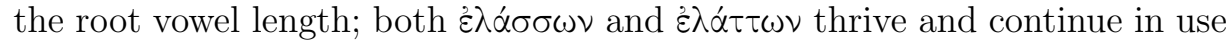
into the Koiné with hundreds of examples. There are far fewer examples of Koiné $\vartheta \alpha \dot{\tau} \tau \omega \nu$, but we do find it in early Christian literature. On the other hand, the forms to which Herodian attributes short vowels never occur in the Koiné.

The difficult example of $\mu \alpha \dot{\sigma} \sigma \sigma \omega \nu$ cannot be handled in quite the same fashion. Herodian treats the root vowel as short and, under this scheme, this is consistent with the fact that it is not found at all in the Koiné. It seems likely that the accentuation of neuter singular $\mu \tilde{\alpha} \sigma \sigma o v$ merely followed that of $\vartheta \tilde{\alpha} \sigma \sigma o \nu, \dot{\varepsilon} \lambda \tilde{\alpha} \sigma \sigma o \nu$, and $\tilde{\alpha} \sigma \sigma o \nu$, being in effect an artifact of the textual tradition rather than a real linguistic feature. All things being considered, it seems pretty certain that we should suppose an original short vowel in $\mu \check{\alpha} \sigma \sigma \omega \nu,-o \nu$.

The idea that the linguistic features being described in Herodian's account belong to the contemporary Koiné would fit well with Probert's (2006:74-9 and 2011:esp.284-5) arguments that Herodian used the educated Koiné as the standard against which to judge linguistic variation, certainly when it came to questions of accentuation.

However, this explanation raises the question how Herodian could have known that comparatives which were not preserved in Koiné had short vowels. It is not an obvious inference, given that all such primary comparatives surviving into the Koine have a long vowel or a heavy syllable in the root

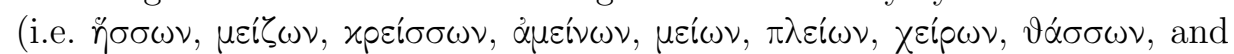
$\dot{\varepsilon} \lambda \dot{\alpha} \sigma \sigma \omega \nu){ }^{33}$ It is possible that such knowledge reflects traditions of recitation of Homer and other poetry which preserved the original vowel lengths in such forms. ${ }^{34}$ An alternative, and perhaps more likely suggestion, would be that Herodian felt free to infer the short vowel of $\pi \dot{\alpha} \sigma \sigma \omega \nu, \gamma \lambda \dot{\sigma} \sigma \sigma \omega \nu, \beta \dot{\alpha} \sigma \sigma \omega \nu$, and $\beta p \alpha ́ \sigma \sigma \omega \nu$ on the basis of the short root vowel in the positive adjectives

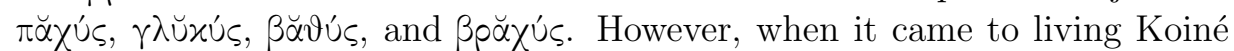
forms such as $\vartheta \alpha \dot{\alpha} \sigma \sigma \omega \nu$ and $\dot{\varepsilon} \lambda \dot{\alpha} \sigma \sigma \omega \nu$, the clear etymological connections with $\dot{\varepsilon} \lambda \breve{\alpha} \chi \mathcal{u}^{\prime} \varsigma$ and $\tau \breve{\alpha} \chi \cup \dot{v} \varsigma$ were not sufficient to override the force of tradition and contemporary usage.

\footnotetext{
${ }^{33}$ These Koiné forms were gathered from a survey of Mayser (1906), Mayser and Schmoll (1970), Gignac (1976-1981) and Danker (2000).

${ }^{34}$ For possible evidence for such a tradition, see West (1981:esp. 114-5) and Probert (2006:33-46).
} 


\section{References}

Bachmann, G.L.E. 1828. Anecdota Graeca, vol.1 (Leipzig), 425-50

Beekes, R.S.P. 2010. Etymological Dictionary of Greek, 2 vols (Leiden-Boston)

Cohn, L. 1888. Konstantin Palaeokappa und Jakob Diassorinos, in: Philologische Abhandlungen M. Hertz zum 70. Geburtstag von ehemaligen Schülern dargebracht (Berlin), 141-43

Chantraine, P. 1999. Dictionnaire étymologique de la langue greque, histoire des mots, avec un Supplément (Paris)

Danker, F.W. (ed.) 2000. A Greek-English lexicon of the New Testament and other early Christian literature, 3rd ed. (Chicago)

Dickey, E. 2007. Ancient Greek Scholarship (Oxford)

Dyck, A. R. 1993. Aelius Herodian: Recent Studies and Prospects for Future Research, in: Haase, W. (ed.), Aufstieg und Niedergang der Römischen Welt, II. 34. 1 (Berlin/New York), 772-94

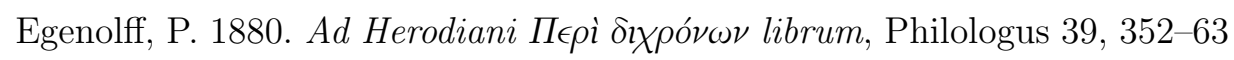

Galland, K. 1882a. De Arcadii qui fertur libro de accentibus, diss. (Strasbourg)

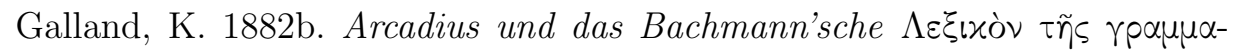

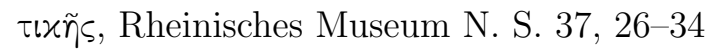

Galland, K. 1883. Die Quantitätslehre Herodians, in:Verhandlungen der 36. Versammlung deutscher Philologen und Schulmänner in Karlsruhe (Leipzig)

Gamillscheg, E., Harlfinger, D. 1981. Repertorium der griechischen Kopisten, 800-1600, Volume 1A (Vienna)

Gamillscheg, E., Harlfinger, D. 1989. Repertorium der griechischen Kopisten, 800-1600, Volume 2A (Vienna)

Gignac, F.T. 1976-1981. A grammar of the Greek papyri of the Roman and Byzantine periods (Milan) 
Hermann, 1801. Emendanda ratione graecae grammaticae (Leipzig), 422-470

Hermann, G. (ed.) 1812. Draconis Stratonicensis liber De metris poeticis (Leipzig)

Hunger, H. 1978. Die hochsprachliche profane Literatur der Byzantiner (Munich)

Kuryłowicz, J. 1956. L’Apophonie en indo-européen (Wroclaw)

Lagerkrantz, O. 1898. Zur griechischen Lautgeschichte (Uppsala)

Lamberterie, C. de 1990. Les adjectifs grecs en -vs, vol. 1/2 (Louvain-laneuve)

Lehrs, K. (ed.) 1857. Herodiani scripta tria emendatiora, 2nd edition (Berlin)

Lejeune, M. 1972. Phonétique historique du mycénien et du grec ancien (Paris)

Lentz, A. (ed.) 1867-70. Herodiani technici reliquiae, 2 vols (Leipzig)

Mayser, E. 1906. Grammatik der griechischen Papyri aus der Ptolemäerzeit, Laut- und Wortlehre (Leipzig)

Mayser, E., Schmoll, H. 1970. Grammatik der Griechischen Papyri aus der Ptolemäerzeit, mit Einschluss der gleichzeitigen Ostraka und der in Ägypten verfassten Inschriften, Band I Laut- und Wortlehre, I. Teil Einleitung und Lautlehre, 2nd edition (Berlin)

Meissner, T. 2006. S-Stem Nouns and Adjectives in Greek and Proto-IndoEuropean, a Diachronic Study in Word Formation (Oxford-New York)

Peters, M. 1980. Untersuchungen zur Vertretung der indogermanischen Laryngale im Griechischen (Vienna)

Probert, P. 2006. Ancient Greek Accentuation. Synchronic Patterns, Frequency Effects, and Prehistory (Oxford) 
Probert, P. 2011. Attic Irregularities: Their Reinterpretation in the Light of Atticism, in: Matthaios, S., Montanari, F., Rengakos, A. (eds.) Ancient scholarship and grammar: archetypes, concepts and contexts (Berlin-New York), 269-290

Pulch, P. 1882. Zu Eudocia, Constantinus Palaeocappa, der Verfasser des Violariums, Hermes 17, 177-192

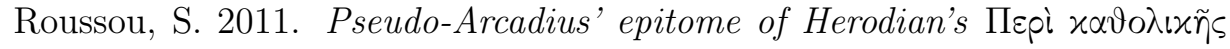

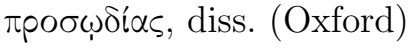

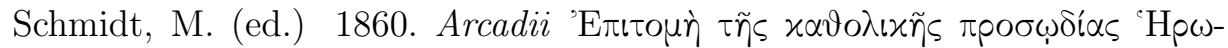

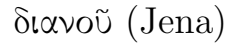

Seiler, H. 1950. Die primären griechischen Steigerungsformen (Zurich)

Sluiter, I. 2011. A Champion of Analogy: Herodian's On Lexical Singularity, in: Matthaios, S., Montanari, F., Rengakos, A. (eds.) Ancient scholarship and grammar: archetypes, concepts and contexts (Berlin-New York), 291310

Wackernagel, J. 1914. Akzentstudien III. Zum homerischen Akzent, Nachrichten von der königlichen Gesellschaft der Wissenschaften zu Göttingen. Philologischhistorische Klasse 1914, 97-130 = Kleine Schriften, vol. 2: 1154-87

West, M.L. 1981. The Singing of Homer and the Modes of Early Greek Music, Journal of Hellenic Studies 101, 113-129 